\title{
Physical Activity of Workers in a Hospital
}

\author{
So Yeon Jun ${ }^{\dagger}$, Jaewon $\operatorname{Kim}^{+}{ }^{\circledR}$, Hyehoon Choi, Joon Sung Kim, Seong Hoon Lim ${ }^{\circledR}$, Bomi Sul ${ }^{\circledR}$ \\ and Bo Young Hong * (D)
}

Department of Rehabilitation Medicine, St. Vincent's Hospital, College of Medicine, The Catholic University of Korea, Seoul 16247, Korea; iamsj17@naver.com (S.Y.J.); jw2356@naver.com (J.K.);

choihyehoon1021@gmail.com (H.C.); svpmr@catholic.ac.kr (J.S.K.); seonghoon@catholic.ac.kr (S.H.L.);

snowspringee@naver.com (B.S.)

* Correspondence: byhong@catholic.ac.kr; Tel.: +82-31-249-7650

+ These authors contributed equally to this work.

Received: 13 January 2019; Accepted: 11 February 2019; Published: 13 February 2019

\begin{abstract}
Purpose: This study aims to evaluate the physical activity of healthcare personnel and the affecting factors of physical activity (PA) in a hospital using an accelerometer device (Actigraph wGT3X-BT). Method: A total of 63 subjects (22 physicians, 19 nurses, and 23 supporting staff) participated and wore an accelerometer for seven days. Among the outputs, the mean counts for a minute, time spent for light, moderate, and vigorous intensity PA, and step count were extracted. As a secondary study, 16 subjects continued for one more week after feedback on their PA of the previous week and counseling to encourage PA. Result: Most of (62/63) the participants fulfilled the recommended amount of $\mathrm{PA}$, which is more than $300 \mathrm{~min}$ of moderate to vigorous physical activity (MVPA). Physicians showed significantly less PA than nurses or supporting staffs: Mean counts per minute (210.4 vs. 476.0 and 441.8 respectively), time in MVPA per week (904.7 min vs. $1471.3 \mathrm{~min}$ and $1451.0 \mathrm{~min})$, and step counts per week $(69,029$ vs. 87,119 and 84,700$)(p<0.001)$. Nurses and supporting staff were not statistically different. There was no significant difference in the PA of workers in the hospital regarding gender and marital status. However, the average calorie expenditure of the child raising group was significantly higher. There was no statistically significant difference in PA before and after counseling. No participants reported a vigorous degree of exercise intensity over the study period. Conclusion: Most of the healthcare personnel met the recommended PA, however, only $57 \%(36 / 63)$ recalled having engaged in MVPA during the study period. The group of physicians showed less PA compared to nurses or supporting staff. Single check-up and counseling were not found to increase PA.
\end{abstract}

Keywords: occupational health; physical activity; healthcare worker

\section{Background}

Physical activity (PA) is defined as any bodily movement produced by skeletal muscles that requires energy expenditure [1]. PA, especially moderate to vigorous intensity PA (MVPA), is highly recommended for preventing cardiovascular diseases, type-2 diabetes, some kinds of cancers, and improving the quality of life [2,3]. The amount of PA has a dose-response relationship with all causes of mortality and cardiovascular diseases [4]. Additionally, PA is shown to counter depression, anxiety disorders, and other mood dysfunctions [5-7]. Therefore, interest in the benefits of PA on specific diseases, health, and well-being has increased, and much research is ongoing [8].

The World Health Organization (WHO) provided recommendations for PA to benefit health in 2010. These recommendations stated that for additional health benefits, adults should increase their moderate intensity aerobic PA to $300 \mathrm{~min}$ per week, or engage in $150 \mathrm{~min}$ of vigorous intensity aerobic PA per week, or an equivalent combination of moderate and vigorous intensity activity [1]. 
Nevertheless, the levels of physical inactivity are rising in many countries and have major implications for the general health of the population worldwide $[9,10]$. About $31 \%$ (range from $17 \%$ in South-East Asia to $43 \%$ in the Americas and Eastern Mediterranean) of overall adults, worldwide, showed physical inactivity [1,11]. The proportion of Korean adults who are regular exercisers is steadily decreasing, and less than $30 \%$ of adults are estimated to be doing the recommended amount of PA [12].

Healthcare personnel endure heavy workloads in emotionally stressful conditions, and they are prone to musculoskeletal problems, psychiatric disorders, such as depression or burnout, and a lower health-related quality of life [13-15]. We assumed that healthcare personnel were at risk of physical inactivity due to the lack of leisure time PA. Owoeye el al. measured the step count using a pedometer among nurses, pharmacists, and physiotherapists and the mean $7396.94 \pm 2714.63$ steps/day was revealed, which was less than the generally accepted recommendation, 10,000 steps/day [16]. However, unlike accelerometer, pedometer does not accurately reflect energy expenditure or intensity of PA [17]. Furthermore, in most recommendations, it is marked as a time of MVPA, which is different from the number of steps. In addition, the previous study did not involve physicians-one of the essential occupations of healthcare workers. The primary goal of this study was to evaluate objectively the amount of PA of healthcare personnel using an accelerometer to find out which factors influence the PA level. In addition, we planned to find out whether there is any improvement in the level of PA when people receive counseling to encourage PA and informative feedback on their PA. To our knowledge, this is the first study to present the PA of healthcare personnel including physicians using an accelerometer, which is more objective than a questionnaire.

\section{Methods}

\subsection{Study Population}

This study was performed at one university hospital from 1 May to 31 August 2017. An institutional review board reviewed the study protocol (VC170ESI0101), and informed consent was obtained from each subject. The inclusion criteria of our study were those (1) who work in the hospital as a physician, nurse, or supporting staff, such as radiographers or patient-transfer workers, etc., (2) aged from 19 to 60 years, (3) who agreed to participate with informed consent. Persons with fractures or other serious medical conditions or social circumstances that limit PA, or those who have two or more days off-duty during one week of study were excluded.

\subsection{Measures}

We used Actigraph wCT3x-BT (ActiGraph, Pensacola, FL, USA) to monitor PA. Actigraph wGT3X-BT is a small accelerometer; it weighs about $19 \mathrm{~g}$ and measures the amount of PA objectively by recording the acceleration of the body movement. The wGT3X-BT has been widely used to capture and record continuous PA. It measures raw acceleration, the number of activity counts carried out, calorie expended, time spent according to intensity of activity; light, moderate, vigorous, and very vigorous intensity PA, average metabolic equivalent of tasks (METs) per hour, the number of steps taken, total device wear time, sleep latency, total hours of sleep, and sleep efficiency.

The participants were told to wear the accelerometer on the wrist of the non-dominant hand for the entire study period all day long including sleep time, except during water-based activities, such as bathing or swimming. It was given on the first day, and the subjects made an appointment to return the device and see the physician to discuss the analyzed results and to receive counseling about the PA on the seventh day. Demographic information was collected with participants' questionnaires on their age, gender, height, weight, occupation, marital status, having kids or not, medical history, and smoking status. On the seventh day, each participant was asked about estimated total wear time per day, how many days, what exercise, and which intensity they did work out, to improve the accuracy of wear time and PA measurement. This was for additional validation of wear time 
and for comparing the accelerometer measurement with the subjectively perceived amount and intensity of physical activity. A simplified form of Korean-version of the International Physical Activity Questionnaire (IPAQ-K) for adults (15-69 years) was used for the questionnaire regarding exercise $[18,19]$. After that, the participants were told about their report of PA status and informed about the WHO recommendation on PA and the evidence-based effects of PA and exercise from a physician. After one-on-one counseling, they were encouraged to be more active and increase PA. After the completion of counseling, they were asked whether they wished to continue for an additional week to check for an increment in PA. If they agreed to continue, they were given the device for the additional week of recording. Participants were supposed to meet the researcher again after a week to discuss whether their PA had increased.

\subsection{Data Analysis}

After the study period, each collected data was extracted and analyzed through the ActiLife software version 6.13.3 (ActiGraph, Pensacola, FL, USA). We adopted the calculation of estimated energy expenditure using the method developed by Freedson et al., 1998 [20]. The activity count collected by accelerometer can be converted as MET $(=1.439008+(0.000795 \times$ counts $/ \mathrm{min}))$. Using the cut-point of MET (light < 3.0, 3.0 $\leq$ moderate < 6.0, $6.0 \leq$ vigorous $<9.0$, very vigorous $\geq 9.0$ ), each activity count was interpreted as light ( $<1952$ counts), moderate (1952-5724 counts), vigorous (5725-9498 counts), and very vigorous ( $>9498$ counts) activity. A sixty seconds epoch was used. The length of bouts was a minimum of 10 consecutive minutes with allowed a drop time of $2 \mathrm{~min}$. Non-wear was defined as a minimum length of $60 \mathrm{~min}$ with an allowed spike level to stop at 100 counts per minute and spike tolerance of $2 \mathrm{~min}$. Wear time was validated using wear time validation tool in ActiLife software and each participants' questionnaire after study. The information on PA, such as the sum of activity counts, time spent in sedentary, light, moderate, vigorous, and very vigorous intensity of PA, maximum average MET per hour, calorie expended per hour, total step count, total wear time, and sleep information were collected.

The participants were categorized into subgroups according to gender, marital status, body mass index (BMI, $\mathrm{kg} / \mathrm{m}^{2}$ ), having children or not, and types of work (physicians, nurses, and supporting staff) to analyze the information on PA. Using the WHO Asia-Pacific region classification of BMI in adult Asians, BMI was classified as underweight (BMI < 18.5), normal $(18.5 \leq \mathrm{BMI}<23)$, and overweight $(B M I \geq 23)[21]$.

\subsection{Statistical Analysis}

The independent $t$-test and one-way ANOVA were used for the normal distribution and the Kruskal-Wallis test was used for the non-normal distribution (subgroups based on occupation or $\mathrm{BMI})$. Regarding marital status, gender, and having kids, an independent $t$-test was used. Maximal average MET per hour score and total sleep time according to the occupation were analyzed with one-way ANOVA. Comparison of data after counseling with initial study, paired t-test was used if parameters are normally distributed and Wilcoxon signed rank test if parameters are not normally distributed. Paired $t$-test was used for mean counts per minute, maximum average MET per hour, light and moderate intensity activity per minute, and average steps count per minute. Wilcoxon signed rank test was used for total wear time and average calorie expended per hour. To identify the correlation between total sleep time and MVPA, Pearson correlation coefficient was used. SPSS version 21.0 (IBM, Armonk, NY, USA) was used and $p<0.05$ was considered statistically significant.

\section{Results}

A total of 65 participants were recruited and enrolled for the study. We set the minimal device wear time at more than 10 hours per day except sleep time according to the frequently accepted minimal wear time [22-24]. Two participants were excluded because of insufficient device wear time. All the devices were returned after the study, and no equipment was proven to have any defect. 
The demographic characteristics of the participants are presented in Table 1. Among the 63 final participants, 22 were physicians, 18 were nurses, and 23 were supporting staff. The mean age was $35.83 \pm 9.13$ years old (range 24-57 years old). Thirty-one were men (32 women) and 32 participants were married. Thirty participants raised a child or children. No participant suffers from a serious medical condition. Among them, 5 had hypertension, 1 had type 2 diabetes mellitus, and 1 had hyperthyroidism. All of them reported that their disease was well controlled with medicine without any complication. No one participated in water-based exercises such as swimming during the study.

The mean wear time was $22.4 \pm 2.6$ hours per day. None of the participants was reported to have reached vigorous or very vigorous intensity of PA. Hence, only time spent for moderate intensity activity was included for MVPA. A total of 62 out of 63 participants (98\%), 21 of 22 (96\%) physicians, and $100 \%$ of nurses and supporting staff, spent over $300 \mathrm{~min}$ in MVPA per week meeting WHO guidelines. Among the different occupation groups, the physicians group showed significantly fewer mean counts per minute (210.4 of physicians vs. 476.0 of nurses and 441.8 of supporting staffs), MVPA per week (904.7 $\mathrm{min}$ of physicians vs. $1471.3 \mathrm{~min}$ of nurses and $1451.0 \mathrm{~min}$ of supporting staffs), and step counts per week (69,029 of physicians vs. 84,700 of nurses and 87,119 of supporting staffs) than the other two groups $(p<0.001)$. Nurses and supporting staff did not show a statistical difference with the above parameters. The maximal average MET per hour, time spent on the light intensity of physical activity (LPA), and calorie expended per hour was not significantly different among the occupation (Tables 2 and 3).

Regarding the groups according to BMI, there were statistically significant differences of calories expended per hour and maximum average MET per hour among all groups $(p<0.001)$. Calorie expended per hour was 55.01, 41.44, and 27.19 and maximum average MET per hour was 3.0, 2.3, and 1.7 in over-, normal, and under-weighted groups, respectively. However, the mean counts per minute, time spent on MVPA and LPA, and step count per week were not statistically different among the groups (Tables 2 and 3).

There was no significant difference in their mean counts per minute, time spent for MVPA and LPA, average calories expended per hour, and step counts according to sex and marital status. Men showed a significantly higher maximum average MET per hour than women $(p<0.05)$. The participants raising children burned significantly more calories per hour than those without children (1088.30 vs. $849.63 \mathrm{kcal} /$ hour, $p=0.037$ ) (Table 3).

Nineteen participants reported that they performed vigorous intensity physical exercise over $20 \mathrm{~min}$ per day at least once a week $(0.75 \pm 1.44$ days). Thirty-six participants reported the completion of moderate intensity PA over $30 \mathrm{~min}$ per day, at least once a week ( $1.43 \pm 1.71$ days). All the participants reported having done LPA over 30 min per day, at least once a week (5.95 \pm 1.57 days) on a questionnaire. All the participants showed sleep latency within the normal range (less than $30 \mathrm{~min}$ ). Total sleep time was $5.88 \pm 1.34$ hours. Sixty-two of 63 participants showed normal sleep efficiency which is over $85 \%(91.99 \pm 3.30)$. The total sleep time revealed no statistical difference among the occupation groups (Table 4). Furthermore, there was no correlation between total sleep time and MVPA (Figure 1).

Sixteen subjects agreed to wear the device for an additional week after receiving feedback of PA of the previous week and counseling. Their mean age was $34.2 \pm 7.4$ years old. Compared with the initial data, the total wear time and light intensity activity per minute, defined as total time in LPA divided by the total wear time was significantly decreased $(p<0.05)$ (Table 5). No participant did vigorous intensity of PA during the subsequent study period. The mean counts per minute, maximum average MET per hour, average calories expended per hour, moderate intensity activity per minute, defined as total time in moderate intensity of PA divided by total wear time, and step counts per minute, which is defined as the total number of steps divided by total wear time did not show significant difference before versus after counseling. 
Table 1. Demographic characteristics of the participants.

\begin{tabular}{lc}
\hline Variable & No. of the Participants \\
\hline Sex & 31 \\
Male & 32 \\
Female & \\
\hline Occupation & 22 \\
Physician & 18 \\
Nurse & 23 \\
$\quad$ Supporting staffs & \\
\hline Marital status & 34 \\
Married & 29 \\
Unmarried & \\
\hline Have kids & 30 \\
With kids & 33 \\
With no kids & \\
\hline BMI (kg/m $\left.{ }^{2}\right)$ & 4 \\
Under-weighted (BMI < 18.5) & 38 \\
Normal weighted $(18.5 \leq$ BMI $<23)$ & 21 \\
$\quad$ Over-weighted (BMI $\geq 23)$ & \\
\hline Smoking & 54 \\
Non-smoker & 9 \\
Smoker & \\
\hline Medical history & 56 \\
None & 5 \\
Hypertension & 1 \\
Diabetes & 1 \\
Hyperthyroidism & \\
\hline
\end{tabular}

Table 2. Physical activity of the participants.

\begin{tabular}{|c|c|c|c|c|c|c|c|c|}
\hline \multirow{3}{*}{ Variable } & \multicolumn{8}{|c|}{ Intensity of activity } \\
\hline & \multicolumn{2}{|c|}{$\begin{array}{l}\text { Light Intensity Activity } \\
\text { per Week (min) }\end{array}$} & \multicolumn{2}{|c|}{$\begin{array}{l}\text { MVPA per Week } \\
\text { (min) }\end{array}$} & \multicolumn{2}{|c|}{$\begin{array}{c}\text { Mean Counts per } \\
\text { Minute }\end{array}$} & \multicolumn{2}{|c|}{$\begin{array}{c}\text { Maximum Average } \\
\text { MET per Hour }\end{array}$} \\
\hline & $\begin{array}{l}\text { Mean } \\
\text { (SEM) }\end{array}$ & $p$-Value & $\begin{array}{l}\text { Mean } \\
\text { (SEM) }\end{array}$ & $p$-Value & $\begin{array}{l}\text { Mean } \\
\text { (SEM) }\end{array}$ & $p$-Value & $\begin{array}{l}\text { Mean } \\
\text { (SEM) }\end{array}$ & $p$-Value \\
\hline \multicolumn{9}{|l|}{ Sex } \\
\hline Male & $\begin{array}{l}3329.5 \\
(151.3)\end{array}$ & 0.451 & $\begin{array}{l}1257.6 \\
(99.7)\end{array}$ & 0.904 & $\begin{array}{l}360.4 \\
(45.0)\end{array}$ & 0.74 & $3.0(1.0)$ & 0.00 \\
\hline Female & $\begin{array}{l}3481.2 \\
(131.6) \\
\end{array}$ & & $\begin{array}{l}1274.2 \\
(95.3)\end{array}$ & & $\begin{array}{l}380.9 \\
(41.7) \\
\end{array}$ & & $2.0(0.1)$ & \\
\hline \multicolumn{9}{|l|}{ Occupation } \\
\hline Physician & $\begin{array}{l}3519.4 \\
(190.6)\end{array}$ & 0435 & $\begin{array}{l}904.7 \\
(82.3)\end{array}$ & $0 \Omega 0$ t & $\begin{array}{l}210.4 \\
(31.8)\end{array}$ & $0 \Omega 0$ † & & 0159 \\
\hline Nurse & $\begin{array}{l}3401.4 \\
(119.0)\end{array}$ & 0.430 & $\begin{array}{l}1471.3 \\
(128.0)\end{array}$ & $0.00^{\circ}$ & $\begin{array}{l}476.0 \\
(59.9)\end{array}$ & $0.00^{\circ}$ & $2.4(0.2)$ & 0.159 \\
\hline Supporting staffs & $\begin{array}{l}3302.5 \\
(184.3) \\
\end{array}$ & & $\begin{array}{l}1451.0 \\
(106.1)\end{array}$ & & $\begin{array}{l}441.8 \\
(48.0) \\
\end{array}$ & & $2.7(0.1)$ & \\
\hline \multicolumn{9}{|l|}{ Marital status } \\
\hline Married & $\begin{array}{l}3503.3 \\
(143.7)\end{array}$ & 0.297 & $\begin{array}{l}1298.2 \\
(88.0)\end{array}$ & 0.614 & $\begin{array}{l}374.1 \\
(38.7)\end{array}$ & 0.908 & $2.6(0.1)$ & 0.075 \\
\hline Unmarried & $\begin{array}{l}3293.0 \\
(135.8) \\
\end{array}$ & & $\begin{array}{l}1228.3 \\
(108.2)\end{array}$ & & $\begin{array}{l}366.9 \\
(48.8)\end{array}$ & & $2.3(0.1)$ & \\
\hline \multicolumn{9}{|l|}{ Have kids } \\
\hline With kids & $\begin{array}{l}3440.2 \\
(142.9)\end{array}$ & 0.75 & $\begin{array}{l}1324.6 \\
(98.7)\end{array}$ & 0.418 & $\begin{array}{l}387.9 \\
(43.2)\end{array}$ & 0.596 & $2.6(0.1)$ & 0.186 \\
\hline Without kids & $\begin{array}{l}3375.9 \\
(141.0) \\
\end{array}$ & & $\begin{array}{l}1212.8 \\
(95.2)\end{array}$ & & $\begin{array}{l}355.3 \\
(43.2) \\
\end{array}$ & & $2.4(0.1)$ & \\
\hline \multicolumn{9}{|l|}{ BMI $\left(\mathrm{kg} / \mathrm{m}^{2}\right)$} \\
\hline $\begin{array}{l}\text { Under-weighted } \\
(\mathrm{BMI}<18.5)\end{array}$ & $\begin{array}{l}3613.8 \\
(266.9)\end{array}$ & & $\begin{array}{c}818.8 \\
(156.3)\end{array}$ & & $\begin{array}{l}187.0 \\
(67.6)\end{array}$ & & $1.7(0.1)$ & \\
\hline $\begin{array}{l}\text { Normal weighted } \\
(18.5 \leq \mathrm{BMI}<23)\end{array}$ & $\begin{array}{l}3437.7 \\
(121.0)\end{array}$ & $0.6 / 2$ & $\begin{array}{l}1296.3 \\
(87.6)\end{array}$ & 0.205 & $\begin{array}{l}386.0 \\
(38.3)\end{array}$ & 0.219 & $2.3(0.1)$ & $0.00 \mp$ \\
\hline Over-weighted & 3310.6 & & 1296.5 & & 378.4 & & $3.0(0.1)$ & \\
\hline$(\mathrm{BMI} \geq 23)$ & (201.0) & & $(122.6)$ & & $(56.8)$ & & $0.0(0.1)$ & \\
\hline
\end{tabular}


Table 3. Physical activity of the participants.

\begin{tabular}{|c|c|c|c|c|c|c|c|c|}
\hline \multirow{2}{*}{ Variable } & \multicolumn{2}{|c|}{$\begin{array}{l}\text { Average Kcal per } \\
\text { Hours (kcal) }\end{array}$} & \multicolumn{2}{|c|}{$\begin{array}{c}\text { Steps Counts per } \\
\text { Week }\end{array}$} & \multirow{2}{*}{$\begin{array}{c}\begin{array}{c}\text { Sedentary } \\
\text { Activities (\%) }\end{array} \\
\text { Mean }\end{array}$} & \multicolumn{2}{|c|}{$\begin{array}{c}\text { Light + Moderate } \\
\text { Intensity Activities (\%) }\end{array}$} & \multirow{2}{*}{$\begin{array}{c}\text { Vigorous and Very } \\
\text { Vigorous Intensity } \\
\text { Activity (\%) }\end{array}$} \\
\hline & Mean & $p$-Value & Mean & $p$-Value & & Mean & $p$-Value & \\
\hline \multicolumn{9}{|l|}{ Sex } \\
\hline Male & 1050.67 & \multirow[b]{2}{*}{0.137} & 78,959 & \multirow[b]{2}{*}{0.701} & 51.36 & 48.64 & \multirow[b]{2}{*}{0.455} & 0 \\
\hline Female & 878.63 & & 81,227 & & 49.52 & 50.48 & & 0 \\
\hline \multicolumn{9}{|l|}{ Occupation } \\
\hline Physician & 951.06 & \multirow{3}{*}{0.123} & 69,029 & \multirow{3}{*}{$0.01^{\dagger}$} & 50.77 & 49.23 & \multirow{3}{*}{0.616} & 0 \\
\hline Nurse & 900.66 & & 84,700 & & 48.55 & 51.45 & & 0 \\
\hline Supporting staffs & 1023.90 & & 87,119 & & 51.56 & 48.44 & & 0 \\
\hline \multicolumn{9}{|l|}{ Marital status } \\
\hline Married & 993.37 & \multirow{2}{*}{0.6} & 81,252 & \multirow{2}{*}{0.695} & 48.99 & 51.01 & \multirow{2}{*}{0.234} & 0 \\
\hline Unmarried & 932.22 & & 78,934 & & 51.91 & 48.09 & & 0 \\
\hline \multicolumn{9}{|l|}{ Have kids } \\
\hline With kids & 1088.30 & \multirow{2}{*}{0.037} & 83,698 & \multirow{2}{*}{0.245} & 49.09 & 50.91 & \multirow{2}{*}{0.3} & 0 \\
\hline Without kids & 849.63 & & 76,850 & & 51.64 & 48.36 & & 0 \\
\hline \multicolumn{9}{|l|}{ BMI $\left(\mathrm{kg} / \mathrm{m}^{2}\right)$} \\
\hline $\begin{array}{l}\text { Under-weighted } \\
\text { (BMI < 18.5) }\end{array}$ & 27.19 & \multirow{3}{*}{$<0.001 \ddagger$} & 66,340 & \multirow{3}{*}{0.288} & 53.39 & 46.61 & \multirow{3}{*}{0.48} & 0 \\
\hline $\begin{array}{l}\text { Normal weighted } \\
(18.5 \leq \mathrm{BMI}<23)\end{array}$ & 41.44 & & 81,051 & & 50.36 & 49.64 & & 0 \\
\hline $\begin{array}{l}\text { Over-weighted } \\
(\mathrm{BMI} \geq 23)\end{array}$ & 55.01 & & 81,032 & & 49.93 & 50.03 & & 0 \\
\hline
\end{tabular}

${ }^{\dagger}$ Significantly different between physicians and nurses or supporting staff, $\ddagger$ significantly different among all groups, $p<0.05$.

Table 4. Exercise reported with questionnaire and sleep acquired by accelerometer.

\begin{tabular}{lcc}
\hline Variable & Mean \pm SD & $p$-Value \\
\hline Exercise record by questionnaire (No. (d)) & & \\
$\quad$ Light intensity & $63(5.95 \pm 1.57)$ & \\
$\quad$ Moderate intensity & $36(1.43 \pm 1.71)$ & \\
$\quad$ Vigorous intensity & $19(0.75 \pm 1.44)$ & \\
$\quad$ Moderate to vigorous intensity & $36(2.17 \pm 2.83)$ & \\
\hline Total Sleep & & \\
Sleep time (h) & $5.88 \pm 1.34$ & \\
Efficiency (\%) & $91.99 \pm 3.30$ & \\
\hline Sleep time (h) & & 0.27 \\
Physician & $5.55 \pm 1.11$ & \\
$\quad$ Nurse & $6.24 \pm 1.36$ & \\
Supporting staffs & $5.92 \pm 1.49$ & \\
\hline
\end{tabular}

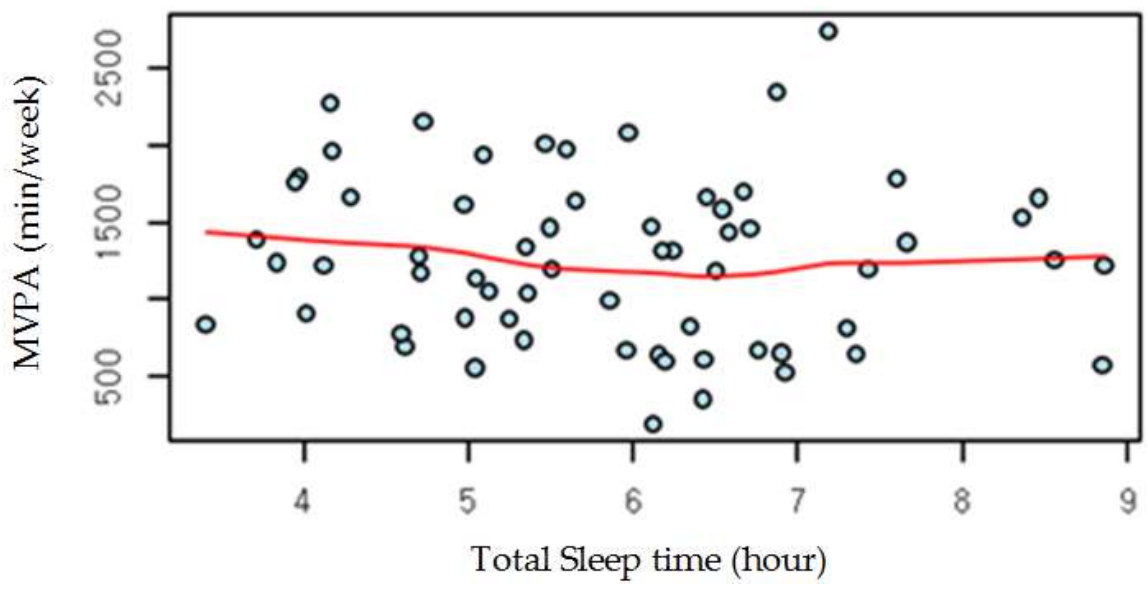

Figure 1. Correlation between total sleep time and moderate to vigorous intensity physical activity (MVPA). 
Table 5. Comparison of physical activity before and after counseling.

\begin{tabular}{|c|c|c|c|c|c|c|c|c|}
\hline \multirow[b]{2}{*}{ Test } & \multicolumn{8}{|c|}{ Mean (SEM) } \\
\hline & $\begin{array}{c}\text { Total } \\
\text { Wear } \\
\text { Time per } \\
\text { Day (hr) }\end{array}$ & $\begin{array}{c}\text { Mean } \\
\text { Counts } \\
\text { per } \\
\text { Minute }\end{array}$ & $\begin{array}{l}\text { Maximum } \\
\text { Average } \\
\text { MET per } \\
\text { Hour }\end{array}$ & $\begin{array}{c}\text { Light } \\
\text { Intensity } \\
\text { Activity } \\
\text { per } \\
\text { Minute * }\end{array}$ & $\begin{array}{c}\text { Moderate } \\
\text { Intensity } \\
\text { Activity } \\
\text { per } \\
\text { Minute * }\end{array}$ & $\begin{array}{c}\text { Vigorous } \\
\text { and Very } \\
\text { Vigorous } \\
\text { Intensity } \\
\text { Activity (\%) }\end{array}$ & $\begin{array}{c}\text { Average } \\
\text { Calorie } \\
\text { Expended } \\
\text { per Hours } \\
\text { (kcal) }\end{array}$ & $\begin{array}{c}\text { Average Steps } \\
\text { Count per } \\
\text { Minute }^{\dagger}\end{array}$ \\
\hline Initial & $21.9(0.8)$ & $\begin{array}{l}395.7 \\
(72.4)\end{array}$ & $2.6(0.1)$ & $0.34(0.03)$ & $0.14(0.02)$ & 0 & 46.53 & 8.3 \\
\hline $\begin{array}{c}\text { After } \\
\text { counseling }\end{array}$ & $16.2(1.1)$ & $\begin{array}{c}413.5 \\
(100.9)\end{array}$ & $2.6(0.2)$ & $0.25(0.02)$ & $0.13(0.02)$ & 0 & 38.25 & 7.6 \\
\hline$p$-Value & 0.003 & 0.975 & 0.594 & 0.03 & 0.79 & - & 0.23 & 0.334 \\
\hline
\end{tabular}

${ }^{*}$ Light/moderate intensity activity per minute is defined as the total time in light/moderate intensity of physical activity divided by total wear time. ${ }^{\dagger}$ Average step count per minute is defined as the total number of steps divided by total wear time.

\section{Discussion}

This study provides the PA status of healthcare personnel using the accelerometer and how various factors, such as sex, occupation, marital status, having kids or not, and BMI effect the parameters of PA. Unexpectedly, the time spent in MVPA of the most of healthcare personnel met WHO guidelines [1,25]. Although $30 \%$ of participants (16 of 63 ) reported that they had engaged in vigorous activity for $0.75 \pm$ 1.44 days, no one did vigorous intensity activity in data gathered by an accelerometer. This mismatch suggests that the PA measured by the questionnaire is quite subjective and may not be accurate [26]. Also, only $57 \%$ of participants ( 36 of 63 ) recalled having done MVPA for $2.17 \pm 2.83$ days, but nearly all of the participants revealed to fulfill MVPA recommendations.

This study shows each person's task in the workspace would be the key factor that determines one's amount of PA. The physician group showed significantly less time spent for MVPA, mean counts per minute, and step count per week, compared to the nurse or supporting staff groups. This might be due to desk-based tasks, aa most of them were in the non-surgery department. The surgical doctors were reluctant to participate because it was cumbersome to wear the device during surgery. Therefore, we cannot exclude the possibility of a selection bias in the physician group. Clemes et al. measured PA among office workers using an accelerometer. It showed time in MVPA was $32 \pm 26 \mathrm{~min}$ per day [27]. The mean time in MVPA of healthcare personnel in this study is $181 \pm 77 \mathrm{~min}$ per day, about five times more than office workers, although only 57\% (36/63) recalled having engaged in MVPA during the study period. This explains the higher intensity of physical loading in hospital workers.

The high intensity of labor with a long work time is an inevitable character of tasks in hospitals. Patient handling or transferring, moving medical equipment, walking around to care for various inpatients or outpatients, and coping with the emergency are included in the tasks. The United States Department of Labor 2005 revealed a higher musculoskeletal disorder rates among healthcare practitioners [28]. Lorusso, A. reviewed musculoskeletal disorders among nursing personnel of whom $33 \%$ to $86 \%$ had low back pain [29]. These studies are in line with our results showing that healthcare personnel deal with physically high intensity tasks.

Concerning gender, men showed higher calorie expended per hour than women, whereas women had higher step counts, mean counts per minute and time in MVPA, but neither was statistically significant. The married group showed a tendency toward higher PA and calorie expended per hour, number of steps, and mean counts per minute and time in MVPA than the single group, irrespective of gender, though it was not statistically significant. Interestingly, the group who raised children showed significantly higher calorie expended per hour than the others, which may be due to additional housework.

Additionally, we aimed to figure out if the extent of PA would change after feedback and counseling. However, there was a significantly decreased wear time during the second time given that hot and humid weather might hinder one from wear the device all day long. Again, nobody did vigorous exercise. In the secondary study, all the parameters showing PA were not improved. 
The participants became aware of a lack of vigorous activity and recognized the need for PA; however, lifestyle modification or effort to exercise was not to be seen in a week. This result suggests that single counseling or encouraging is insufficient to lead to a prompt change in PA. There have been many studies that reveal the effective ways to increase PA. In a study, internet-based PA intervention, with self-monitoring, personalized goal setting, and interaction with other participants and study staff, was conducted on women with a family history of breast cancer. It revealed significantly increased MVPA at 3 months and 5 months [30]. Another study showed that setting a personalized target to reach an average step count per day using a pedometer was significantly effective to improve PA in patients with chronic obstructive pulmonary disease [31]. Compared with our study, their interventions were done with more specific and personalized goals. We offered to counsel and emphasized the importance of enhancing PA and subsequent health effects, but no specific goal to improve their PA was given. Also, our participants were all healthy and relatively young without underlying severe diseases, and their concern for health might not be as much as those with illnesses. Besides, the time spent working, including commute time, was almost half a day and the participants were probably too busy to make time for exercise. It seems that both internal and external factors such as motivation and work loading are obstacles to improving PA.

Many people state 'lack of time' as a major barrier for exercise. Over $50 \%$ of employees reported that they have little time to exercise because of a busy work schedule [32]. Also, a busy home or family schedule was a barrier for nearly $50 \%$ of participants [32]. Besides, over $75 \%$ of workers are employed in sedentary jobs [10]. Therefore, increasing PA in the workplace can be one solution to enhance PA. Due to the nature of hospital tasks, most of the healthcare personnel meet the MVPA criteria of recommendation, but enhancing PA among office workers is not easy. Nevertheless, some studies have been conducted to increase PA in the workplace. John et al. performed an empirical study of treadmill workstations-sedentary office-workers were made to work while walking. It revealed that standing, stepping time and total steps per day were significantly increased. Also, lipid profile and the circumference of the hip and waist were improved [33]. Another study included the intervention strategies introduced was a workplace walking program which encouraged walking instead of sitting during work tasks [34]. Other study assigned their participants a mandatory activity of middle-to-high intensity for $2.5 \mathrm{~h}$ per week during their work hours [35]. However, whether the above-mentioned strategies are effective in promoting PA is questionable since their evidence proved to be insufficient or less significant [36]. More effective and attractive strategies to get the participants involved in PA at their workplaces are promised in the future.

This study has several limitations. First, only a small number of the workers participated. The number of participants was smaller than expected which may be due to less interest in PA and the cumbersome of wearing the device in a hospital working environment. Especially, the number of the under-weight group was four, and this is too small a sample size to interpret as conclusive. The study was exploratory research to observe the PA status of workers in a hospital, hence, power calculation was not done initially. However, there have been a few studies on the PA of healthcare personnel, therefore this study is meaningful that our results show PA status of healthcare personnel with an objective manner. Further research with a more significant number of participants is needed for more in-depth analysis. Second, the working hours of the subjects were not consistent, which is a characteristic of healthcare personnel. Their working time was divided into day and night time, including the three eight-hour shift schedules of nurses. Additionally, because of the small number of participants, data during work time and off-duty time were not considered. Despite these limitations, we were able to study PA based on each's characteristics within one common workplace.

\section{Conclusions}

Most of the participants fulfilled the recommended level and amount of PA despite the lack of vigorous intensity of PA. This implicates that the physical intensity of tasks of the hospital is high and health care workers are not much involved in leisure activity for individual exercise. Among 
subgroups, the physicians revealed to have significantly less PA compared to nurses or supporting staff. Gender and marital status did not influence the PA of workers in the hospital. However, raising a child may increase the average calorie expenditure. Also, individual counseling, including education on the positive impact and necessity of PA was not effective towards increasing PA. This shows that a single intervention without an individualized goal and checkup might be insufficient to lead to a successful outcome. To improve health, we need to constantly pay attention to increase PA in daily life, including in the workplace. Future research should focus on practical ways to enhance PA, including strategies which can be applied in the workplace.

Author Contributions: Conceptualization, B.Y.H. and S.Y.J.; methodology, B.Y.H.; software, B.Y.H.; validation, H.C. and B.S.; formal analysis, S.Y.J. and J.K.; investigation, B.Y.H. and S.Y.J. ; resources, B.Y.H.; data curation, S.Y.J., J.K., and H.C.; writing—original draft preparation, S.Y.J. and J.K.; writing—review \& editing, B.Y.H., J.K., and B.S.; visualization, S.Y.J; supervision, S.H.L. and J.S.K.; project administration, B.Y.H.; funding acquisition, B.Y.H.

Funding: This research was supported by the Basic Science Research Program through the National Research Foundation of Korea (NRF); NRF-2017R1C1B5017423.

Conflicts of Interest: The authors declare no conflict of interest.

\section{References}

1. World Health Organization. Global Recommendations on Physical Activity for Health; World Health Organization: Geneva, Switzerland, 2010.

2. Haskell, W.L.; Lee, I.M.; Pate, R.R.; Powell, K.E.; Blair, S.N.; Franklin, B.A.; Macera, C.A.; Heath, G.W.; Thompson, P.D.; Bauman, A. Physical Activity and Public Health: Updated Recommendation for Adults from the American College of Sports Medicine and the American Heart Association. Med. Sci. Sports Exerc. 2007, 39, 1423-1434. [CrossRef] [PubMed]

3. Sluik, D.; Buijsse, B.; Muckelbauer, R.; Kaaks, R.; Teucher, B.; Johnsen, N.F.; Tjonneland, A.; Overvad, K.; Ostergaard, J.N.; Amiano, P.; et al. Physical Activity and Mortality in Individuals with Diabetes Mellitus: A Prospective Study and Meta-Analysis. Arch. Intern. Med. 2012, 172, 1285-1295. [CrossRef] [PubMed]

4. Kodama, S.; Tanaka, S.; Heianza, Y.; Fujihara, K.; Horikawa, C.; Shimano, H.; Saito, K.; Yamada, N.; Ohashi, Y.; Sone, H. Association between Physical Activity and Risk of All-Cause Mortality and Cardiovascular Disease in Patients with Diabetes: A Meta-Analysis. Diabetes Care 2013, 36, 471-479. [CrossRef] [PubMed]

5. Blake, H.; Mo, P.; Malik, S.; Thomas, S. How Effective Are Physical Activity Interventions for Alleviating Depressive Symptoms in Older People? A Systematic Review. Clin. Rehabil. 2009, 23, 873-887. [CrossRef] [PubMed]

6. Carek, P.J.; Laibstain, S.E.; Carek, S.M. Exercise for the Treatment of Depression and Anxiety. Int. J. Psychiatry Med. 2011, 41, 15-28. [CrossRef] [PubMed]

7. Byrne, A.; Byrne, D.G. The Effect of Exercise on Depression, Anxiety and Other Mood States: A Review. J. Psychosom. Res. 1994, 37, 565-574. [CrossRef]

8. Hildebrandt, V.H.; Bongers, P.M.; Dul, J.; van Dijk, F.J.; Kemper, H.C. The Relationship between Leisure Time, Physical Activities and Musculoskeletal Symptoms and Disability in Worker Populations. Int. Arch. Occup. Environ. Health 2000, 73, 507-518. [CrossRef] [PubMed]

9. Guthold, R.; Stevens, G.A.; Riley, L.M.; Bull, F.C. Worldwide Trends in Insufficient Physical Activity from 2001 to 2016: A Pooled Analysis of 358 Population-Based Surveys with 1.9 Million Participants. Lancet Glob. Health 2018, 6, e1077-e1086. [CrossRef]

10. Brownson, R.C.; Boehmer, T.K.; Luke, D.A. Declining Rates of Physical Activity in the United States: What Are the Contributors? Annu. Rev. Public Health 2005, 26, 421-443. [CrossRef] [PubMed]

11. Hallal, P.C.; Andersen, L.B.; Bull, F.C.; Guthold, R.; Haskell, W.; Ekelund, U. Global Physical Activity Levels: Surveillance Progress, Pitfalls, and Prospects. Lancet 2012, 380, 247-257. [CrossRef]

12. Chae, D.H.; Kim, S.H.; Lee, C.Y. A Study on Gender Differences in Influencing Factors of Office Workers' Physical Activity. J. Korean Acad. Community Health Nurs. 2013, 24, 273. [CrossRef]

13. Suner-Soler, R.; Grau-Martin, A.; Font-Mayolas, S.; Gras, M.E.; Bertran, C.; Sullman, M.J. Burnout and Quality of Life among Spanish Healthcare Personnel. J. Psychiatr. Ment. Health Nurs. 2013, 20, 305-313. [CrossRef] [PubMed] 
14. Koyuncu, N.; Karcioglu, O. Musculoskeletal Complaints in Healthcare Personnel in Hospital: An Interdepartmental, Cross-Sectional Comparison. Medicine 2018, 97, e12597. [CrossRef] [PubMed]

15. Glass, D.C.; McKnight, J.D.; Valdimarsdottir, H. Depression, Burnout, and Perceptions of Control in Hospital Nurses. J. Consult. Clin. Psychol. 1993, 61, 147-155. [CrossRef] [PubMed]

16. Owoeye, O.; Tomori, A.; Akinbo, S. Pedometer-determined physical activity profile of healthcare professionals in a Nigerian tertiary hospital. Niger Med. J. 2016, 57, 99-103. [CrossRef] [PubMed]

17. Tudor-Locke, C.; Williams, J.E.; Reis, J.P.; Pluto, D. Utility of pedometers for assessing physical activity. Sports Med. 2002, 32, 795-808. [CrossRef] [PubMed]

18. Craig, C.L.; Marshall, A.L.; Sjöström, M.; Bauman, A.E.; Booth, M.L.; Ainsworth, B.E.; Pratt, M.; Ekelund, U.; Yngve, A.; Sallis, J.F.; et al. International physical activity questionnaire: 12-country reliability and validity. Med. Sci. Sports Exerc. 2003, 35, 1381-1395. [CrossRef] [PubMed]

19. International Physical Activity Questionnaire (IPAQ). Available online: https://sites.google.com/site/ theipaq/questionnaire_links (accessed on 4 February 2019).

20. Freedson, P.S.; Melanson, E.; Sirard, J. Calibration of the Computer Science and Applications, Inc. accelerometer. Med. Sci. Sports Exerc. 1998, 30, 777-781. [CrossRef] [PubMed]

21. World Health Organization. The Asia-Pacific Perspective: Redefining Obesity and Its Treatment; Health Communications Australia: Sydney, Australia, 2000.

22. Herrmann, S.D.; Barreira, T.V.; Kang, M.; Ainsworth, B.E. How Many Hours Are Enough? Accelerometer Wear Time May Provide Bias in Daily Activity Estimates. J. Phys. Act. Health 2013, 10, 742-749. [CrossRef] [PubMed]

23. Troiano, R.P.; Berrigan, D.; Dodd, K.W.; Masse, L.C.; Tilert, T.; McDowell, M. Physical activity in the United States measured by accelerometer. Med. Sci. Sports Exerc. 2008, 40, 181. [CrossRef] [PubMed]

24. Hagstromer, M.; Oja, P.; Sjostrom, M. Physical Activity and Inactivity in an Adult Population Assessed by Accelerometry. Med. Sci. Sports Exerc. 2007, 39, 1502-1508. [CrossRef] [PubMed]

25. Piercy, K.L.; Troiano, R.P.; Ballard, R.M.; Carlson, S.A.; Fulton, J.E.; Galuska, D.A.; George, S.M.; Olson, R.D. The physical activity guidelines for Americans. JAMA 2018, 320, 2020-2028. [CrossRef] [PubMed]

26. Duncan, G.E.; Sydeman, S.J.; Perri, M.G.; Limacher, M.C.; Martin, A.D. Can sedentary adults accurately recall the intensity of their physical activity? Prev. Med. 2001, 33, 18-26. [CrossRef] [PubMed]

27. Clemes, S.A.; O'connell, S.E.; Edwardson, C.L. Office workers' objectively measured sedentary behavior and physical activity during and outside working hours. J. Occup. Environ. Med. 2014, 56, 298-303. [CrossRef] [PubMed]

28. Bureau of Labor Statistics. Lost Work Time Injuries and Illnesses: Characteristics and Resulting Time away from Work 2004; US Department of Labor: Washington, DC, USA, 2005.

29. Lorusso, A.; Bruno, S.; L'abbate, N. A review of low back pain and musculoskeletal disorders among Italian nursing personnel. Ind. Health 2007, 45, 637-644. [CrossRef] [PubMed]

30. Hartman, S.J.; Dunsiger, S.I.; Marinac, C.R.; Marcus, B.H.; Rosen, R.K.; Gans, K.M. Internet-Based Physical Activity Intervention for Women with a Family History of Breast Cancer. Health Psychol. 2015, 34, 1296-1304. [CrossRef] [PubMed]

31. Mendoza, L.; Horta, P.; Espinoza, J.; Aguilera, M.; Balmaceda, N.; Castro, A.; Ruiz, M.; Diaz, O.; Hopkinson, N.S. Pedometers to Enhance Physical Activity in Copd: A Randomised Controlled Trial. Eur. Respir. J. 2015, 45, 347-354. [CrossRef] [PubMed]

32. Bowles, H.R.; Morrow, J.R., Jr.; Leonard, B.L.; Hawkins, M.; Couzelis, P.M. The Association between Physical Activity Behavior and Commonly Reported Barriers in a Worksite Population. Res. Q. Exerc. Sport 2002, 73, 464-470. [CrossRef] [PubMed]

33. John, D.; Thompson, D.L.; Raynor, H.; Bielak, K.; Rider, B.; Bassett, D.R. Treadmill Workstations: A Worksite Physical Activity Intervention in Overweight and Obese Office Workers. J. Phys. Act. Health 2011, 8, 1034-1043. [CrossRef] [PubMed]

34. Gilson, N.D.; Ainsworth, B.; Biddle, S.; Faulkner, G.; Murphy, M.H.; Niven, A.; Pringle, A.; Puig-Ribera, A.; Stathi, A.; Umstattd, M.R. A Multi-Site Comparison of Environmental Characteristics to Support Workplace Walking. Prev. Med. 2009, 49, 21-23. [CrossRef] [PubMed] 
35. Von Thiele Schwarz, U.; Lindfors, P.; Lundberg, U. Health-Related Effects of Worksite Interventions Involving Physical Exercise and Reduced Workhours. Scand. J. Work Environ. Health 2008, 34, 179-188. [CrossRef] [PubMed]

36. Malik, S.H.; Blake, H.; Suggs, L.S. A Systematic Review of Workplace Health Promotion Interventions for Increasing Physical Activity. Br. J. Health Psychol. 2014, 19, 149-180. [CrossRef] [PubMed] 